\title{
Jean-Philippe Frimat wins ABC Best Paper Award
}

\author{
Andrea Pfeifer
}

Published online: 18 April 2010

(C) Springer-Verlag 2010

This year's Best Paper Award for outstanding work published in Analytical and Bioanalytical Chemistry (ABC) in 2009 goes to Jean-Philippe Frimat (29), who is lead author of the paper "Plasma stencilling methods for cell patterning". This cell patterning method enables biologists to mimic biological cell surfaces, allowing for cellular morphology studies as well as development of novel methodologies for quantitative determination of cellular components. The technique shows high potential for applications not only in cellular analysis, but also in the differentiation between normal and diseased cells. Accompanied by EUR 1,000, the Award is sponsored by Springer to acknowledge the work of an exceptional young scientist. The article "Plasma stencilling methods for cell patterning", by Jean-Philippe Frimat, Heike Menne, Antje Michels, Silke Kittel, Raffael Kettler, Sabine Borgmann, Joachim Franzke and Jonathan West, is freely available online on SpringerLink at http://www.springerlink.com/content/? $\mathrm{k}=10.1007 \% 2 \mathrm{fs} 00216-009-2824-7$.

\section{Who is Jean-Philippe Frimat?}

Jean-Phillippe Frimat talks about his research, his motivations and about himself to Andrea Pfeifer.

\footnotetext{
A. Pfeifer $(\triangle)$

Analytical and Bioanalytical Chemistry, Springer,

Tiergartenstr. 17,

69121 Heidelberg, Germany

e-mail: abc@springer.com
}

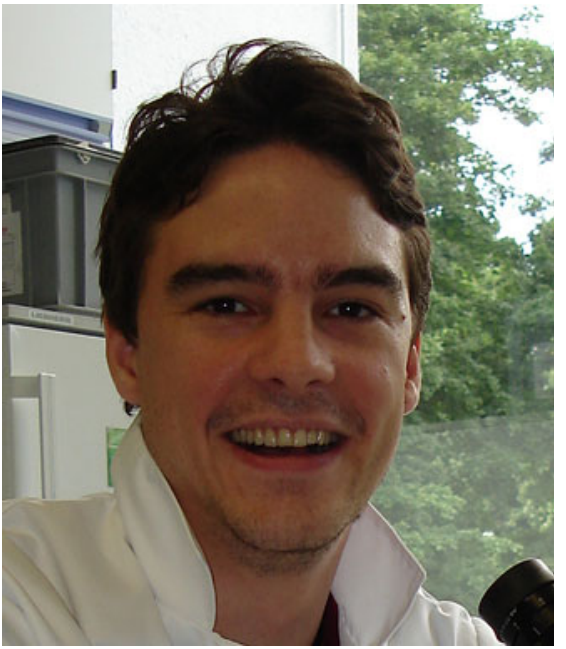

Jean-Philippe Frimat completed his undergraduate diploma at The University of Edinburgh in Medical Microbiology (BSc Hons) in 2004 and obtained his MSc from The University of Manchester in Immunology and Immunogenetics in 2006. In 2007 he started his PhD in Dr. Joachim Franzke's Miniaturisation Department under the supervision of Dr. Jonathan West. His research is focused on the development of micropatterning technologies for quantitative and reproducible analysis of cellular responses. Key examples of his latest work include a microarray system for neurotoxicity testing and a microfluidic approach for studying communication processes during heterotypic single cell co-culture.

\section{What is your motivation to do research combining cell analysis and microtechnology?}

The motivation behind combining cell analysis and microtechnology is to enable cell biology assays to be spatially standardized with high reproducibility. Microtechnologies offer precision control at the same length scales as single cells and tissues. Microtechnologies can be used for the 
quantitative analysis of cellular responses in both research and commercial applications.

Where do you see this field headed and how do you see it influencing cell biology?

I see microtechnologies being increasingly used for the spatial control of cells. These systems can be used to make cell biology more accurate, reproducible and quantitative. This 'spatially standardized cell biology' vision places cell micropatterning as an invaluable and everyday part of quantitative cell biology, ultimately resulting in a change in the way scientists think about the possibilities of cell biology.

\section{Why do you think your work merits the $\mathrm{ABC}$ Best Paper Award?}

I am very proud of the award because the work presented is truly interdisciplinary, combining plasma technology, material patterning, surface analysis and cell biology. The paper demonstrates that our cell patterning method is widely applicable with all tested mammalian cell lines successfully patterned. This simple and fast approach can easily be adopted by biologists with a view to the widespread impact of cell patterning in biological research.

\section{How does this work relate to your research at ISAS?}

My research at ISAS is focused on the development of cell patterning methodologies as reproducible tools for quantitative analysis of cellular responses. The published article presents a novel approach to pattern established cell lines without the need for direct protein deposition steps. The knowledge gained from this plasma stenciling approach has been adopted to address challenges in neurotoxicology, tumour spheroid biology and co-culture research.

\section{What's the trickiest problem you've had to overcome in that research? How did you solve it?}

The trickiest problem was to generate microarrays of cell sized adhesion islands. We solved this problem by constructing a dielectric barrier discharge (DBD) system comprising a bundle of glass microcapillaries (see $\mathrm{ABC}$ front cover). In this way, we were able to generate parallel plasma arrays for patterning small clusters of cells.
How would you explain your research to a child?

I would describe my work as constructing a home for cells by using a gun to fire lightning bolts on which cells can live. To be honest, I think any child would be impressed by the plasma gun (Tesla coil) itself, regardless of understanding the science behind it!!!

\section{What was the best advice you ever received?}

The best advice I ever received was:

'Simplicity is the ultimate sophistication' (Leonardo da Vinci)

\section{Whom do you admire the most and why?}

Nikola Tesla is my source of inspiration and admiration. The impact of the technologies invented by Tesla has revolutionized science as well as society. With over a 1000 patents ranging in disciplines from electromagnetism to electromechanical engineering, from robotics to remote control technologies, from radar and computer sciences to wireless transmissions, Tesla has single handedly shaped our world.

\section{What are your future plans?}

My ultimate goal is to head my own laboratory and develop innovative microchip-based assays to tackle outstanding challenges in cell biology. I believe that the use of microtechnologies in cell biology can contribute towards a better understanding of cellular processes and can be used to improve the control, organization and quantification of cellular responses. But on a shorter time scale, I would like to finish writing up my thesis before summer and watch the 2010 World Cup.

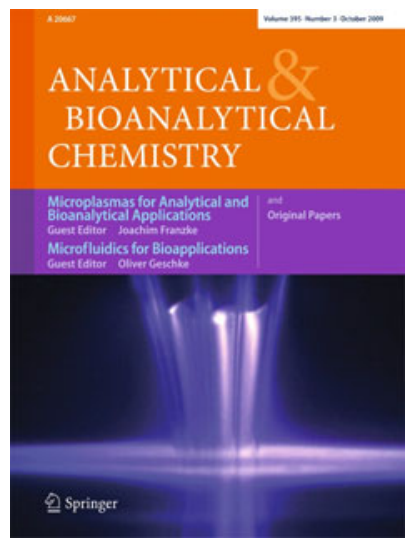

The winning paper was published in the special issue on "Microplasmas for Analytical and Bioanalytical Applications", with Guest Editor Joachim Franzke. The cover image was taken from a figure in Jean-Philippe Frimat's award-winning paper. 